\title{
Field surveys of egg mortality and indigenous egg parasitoids of the brown marmorated stink bug, Halyomorpha halys, in ornamental nurseries in the mid-Atlantic region of the USA
}

\author{
Ashley L. Jones ${ }^{1}$ - David E. Jennings ${ }^{1}$ - Cerruti R. R. Hooks ${ }^{1}$ - Paula M. Shrewsbury ${ }^{1}$
}

Received: 31 January 2017/Revised: 23 May 2017 / Accepted: 30 May 2017/Published online: 5 June 2017

(C) The Author(s) 2017. This article is an open access publication

\begin{abstract}
The brown marmorated stink bug, Halyomorpha halys (Stål), is an invasive species native to regions of China, Japan, Korea, and Taiwan. In its native and introduced range, $H$. halys is considered a pest of tree fruits, vegetables, legumes, and ornamental trees. The highly polyphagous nature of this insect as well as its vast dispersal capabilities, require an integrated approach to management. Here we focus on the potential impact of indigenous natural enemies on $H$. halys in woody ornamental nurseries in Maryland, USA. We sampled naturally field laid $H$. halys egg masses for mortality and parasitism rates in 2012 and 2013. Overall, egg mortality averaged $54 \%$ for both years, and increased within season and between years. The largest source of mortality was from egg parasitoids with mean parasitism rates of 30.73 and $39.63 \%$ in 2012 and 2013, respectively. Mortality from predation was much lower and averaged $4.61 \%$ by chewing and $2.53 \%$ by sucking predators. We found seven species of Hymenopteran egg parasitoids attacking $H$. halys eggs, with Anastatus reduvii being the dominant species comprising 61.17 and $79.12 \%$ of all parasitoids in 2012 and 2013, respectively. The observed increase in parasitism
\end{abstract}

Communicated by T. Haye.

Special Issue: The brown marmorated stink bug Halyomorpha halys an emerging pest of global concern.

Electronic supplementary material The online version of this article (doi:10.1007/s10340-017-0890-8) contains supplementary material, which is available to authorized users.

Paula M. Shrewsbury

pshrewsbury@umd.edu

1 Department of Entomology, University of Maryland, 4112 Plant Sciences Building, College Park, MD 20742, USA over time and female biased sex ratio of parasitoids suggests that native parasitoids may be responding to the novel host, H. halys. Consequently, the use of these native eupelmid egg parasitoids in augmentative or conservation biological control may be a viable $H$. halys management strategy in ornamental nurseries.

Keywords Anastatus reduvii - Native parasitoids . Biological control · Parasitism · Predation

\section{Key message}

- Halyomorpha halys is abundant in ornamental plant nurseries. Over 2 years, we found $H$. halys egg mortality averaging $54.1 \%$, of which hymenopteran parasitoids ( 7 species total) were the primary mortality source $(35.8 \%)$. Predation provided the lowest source of egg mortality $(7.1 \%)$.

- Parasitism increased within seasons and between years. Sex ratio of all parasitoids increased in female bias from 2012 to 2013.

- Anastatus spp. accounted for $98.3 \%$ of parasitism (determined from enclosed parasitoids) suggesting that these native eupelmids contribute to biological control of $H$. halys in nurseries.

\section{Introduction}

Invasive species have been well documented for their detrimental impacts in natural and managed ecosystems and for economic consequences associated with their introductions (Pimentel et al. 2005; Aukema et al. 2011). 
The successful invasion of exotic species into new regions is often attributed, partly, to their escape from natural enemies in their native range where they have a shared evolutionary history (Keane and Crawley 2002). Consequently, re-establishing population control in the invaded range can be an important tool for managing invasive species and providing significant economic benefits (Naranjo et al. 2014).

The brown marmorated stink bug, Halyomorpha halys (Stål), (Hemiptera: Pentatomidae), is an invasive species first detected in the USA in 1996 in Allentown, PA (Hoebeke and Carter 2003; Hamilton 2009). Halyomorpha halys is a highly polyphagous, utilizing over 100 host plant species or cultivars across its native and introduced ranges (Bergmann et al. 2013; Rice et al. 2014; Haye et al. 2015; Bergmann et al. 2016) and economically damaging pest (Leskey et al. 2012; Rice et al. 2014; Haye et al. 2015). Host plants include fruit, row and vegetable crops, and ornamental plants in natural and managed environments (Leskey et al. 2012; Rice et al. 2014; Bergmann et al. 2016). Halyomorpha halys use over 88 woody ornamental plants as feeding and/or oviposition hosts throughout the season (Bernon 2004; Bergmann et al. 2016).

In its native range of Japan, China, and Korea (Hoebeke and Carter 2003), H. halys has several natural enemies, particularly scelionid egg parasitoids such as Trissolcus spp. (Hymenoptera: Scelionidae). Studies performed within its native range show that egg parasitoids may be effective natural enemies of $H$. halys with parasitism rates as high as 84.7\% (Zhang et al. 1993; Chu et al. 1997; Qiu 2007; Hou et al. 2009), suggesting biological control has a potential role in invaded ranges to keep $H$. halys in check. Classical biological control, which entails releasing natural enemies from the home land of the introduced pest, often takes multiple years of host specificity testing and other risk assessment procedures before initial releases of exotic natural enemies can begin (Kenis et al. 2017). Efforts toward classical biological control are well underway in the USA (Rice et al. 2014; Talamas et al. 2015, Herlihy et al. 2016; Santacruz et al. 2017). Recently, an adventive population of $T r$. japonicus, a parasitoid of $H$. halys in its native range, has been confirmed in several US states (Talamas et al. 2015; Herlihy et al. 2016; Milnes and Beers 2016). The distribution, host use, and impact of this adventive population of $\mathrm{Tr}$. japonicus are currently under study (P. Shrewsbury, unpublished).

Though classical biological control is an option, it is also important to elucidate native natural enemies impacts on $H$. halys within its invaded range, and ultimately their potential use in augmentative (rearing and release of native parasitoids) or conservation (habitat manipulation to favor parasitoids) biological control approaches. Several studies have been conducted to examine the identity and impact of native natural enemies on $H$. halys survival in various habitats (Jones et al. 2014; Cornelius et al. 2016; Herlihy et al. 2016; Morrison et al. 2016; Ogburn et al. 2016) within the USA. Overall, impacts on $H$. halys egg mortality tend to vary among habitat types, between predators and parasitoids, and by parasitoid species (Jones et al. 2014; Cornelius et al. 2016; Herlihy et al. 2016; Ogburn et al. 2016). Some of this variation may in part be explained by the diverse types of $H$. halys egg mass used in the studies. For example, when live sentinel (laboratory reared) was compared to naturally laid egg masses of $H$. halys in the field, it was found that parasitism rates, parasitoid community composition, and parasitoid species richness were significantly less for sentinel compared with naturally laid egg masses (Jones et al. 2014).

Ornamental plants play an essential role in the biology and ecology of $H$. halys. As such, it is important to understand the population dynamics of native natural enemies in ornamental plant nurseries and their potential for use in biological control programs. However, to our knowledge, only one previous study has been conducted to examine natural enemy activity in woody ornamental production nurseries (Jones et al. 2014). Nurseries often consist of diverse tree species offering the ability to examine patterns of natural enemy activity on different host plants within a common environment. The present study was conducted to: (1) evaluate mortality factors (e.g., predation, parasitism) affecting $H$. halys eggs, (2) identify indigenous parasitoids associated with $H$. halys eggs, and (3) quantify the impact of egg parasitoids on $H$. halys egg mortality in ornamental nurseries. Effects of study site location and host tree species on egg mortality and how the exposure period of eggs to predation and parasitism impact their mortality was also examined.

\section{Materials and methods}

\section{Study sites and experimental design}

Three field sites in Maryland, USA, were selected for this study. Selected nurseries were known to contain high populations of $H$. halys and an associated high abundance of naturally laid $H$. halys egg masses, which allows for a more realistic and statistically rigorous estimate of parasitoid activity (Jones et al. 2014; Herlihy et al. 2016). The nursery sites and tree species sampled were the same as those used in Jones et al. (2014) which provides a detailed description of sites and trees. Nursery sites included Raemelton Farm in Adamstown, MD (Frederick County) and two additional sites at Ruppert Nurseries in Laytonsville, MD (Montgomery County). Three genera of trees were chosen for monitoring at each nursery site based on preliminary 
observations that $H$. halys used these genera as oviposition hosts (Shrewsbury, unpublished). Trees included Acer rubrum L. 'Franksred' (red maple), Prunus serrulata L. 'Kwanzan' (ornamental cherry), Ulmus americana L. 'Princeton' (American elm), and Ulmus parvifolia Jacq. 'Patriot' (Chinese elm). Two species of elms were used as there were a limited number of any one species at the different sites. The number of trees surveyed for each species varied between nurseries due to differences in abundance of test species at each nursery (Table 1). Each field site was sampled approximately twice weekly throughout the 2012 and 2013 season (from late May to early September) which coincides with the period when $H$. halys is active (Leskey et al. 2015; Bergh et al. 2017).

\section{Field sampling of trees for $\boldsymbol{H}$. halys eggs}

At each sampling event, all tree foliage up to a height of $2.7 \mathrm{~m}$ was searched thoroughly for egg masses laid in the field by $H$. halys. A small percentage of the naturally laid egg masses (92 of $2105=4.4 \%$ ) assessed in this study were used to make comparisons to sentinel egg masses in Jones et al. (2014). At each sampling period, all egg masses present on a tree were assessed. The number of egg masses on a tree varied over time and overall ranged from 0 to $5 \mathrm{egg}$ masses per tree. When located, the leaf containing the egg mass was marked with a piece of colored tape, and the location of the egg mass within the tree was recorded. Egg masses were left in the field for one of two exposure times: either $48 \mathrm{~h}$ (post-marking) or until $H$. halys hatched from the egg mass ( 7 days post-marking). These time periods were chosen to fully assess types of mortality that could vary temporally (48-h time period reducing the potential loss of parasitized eggs to predator consumption, and eggs left out until $H$. halys hatched were targeting mortality potentially due to predation. Egg masses were then collected from trees and transported to the laboratory for further assessment.

\section{Assessment of egg fate}

In the laboratory, each egg mass was placed in a Petri dish (Thermo Fisher Scientific Incorporated, $100 \mathrm{~mm} \times$ $15 \mathrm{~mm})$ in a Percival incubator $\left(25^{\circ} \mathrm{C} \pm 2{ }^{\circ} \mathrm{C}, 16 \mathrm{~L}: 8 \mathrm{D}\right)$.
Individual eggs in each mass were monitored to determine their fate. Emerging $H$. halys nymphs and parasitoids were removed and unhatched eggs were assessed for other causes of mortality. Parasitoids that emerged were placed in $70 \%$ ethanol for later identification. Egg parasitoids were identified according to Dieckhoff (unpublished). The number of parasitoids emerging and their sex were recorded. Females were identified to species, and males were pooled by genus due to difficulty in identification and the lack of taxonomic keys for males. Sex ratio was determined at the genus level since males could be accurately identified to genus but not to species. Eggs where nothing emerged or hatched were further assessed to determine other potential causes of mortality.

Egg fate and mortality factors were assigned to individual eggs within each egg mass with the use of a stereo microscope. Characteristics used in this study concur with those depicted by Morrison et al. (2016) for signs of predation by chewing and sucking predators. Unlike Morrison et al. (2016) this study also characterizes signs of parasitism. Egg fate categories included: "hatched" where $H$. halys emerged from the egg with no apparent mortality (Fig. 1a), "sucked" where there were three or more stylet sheaths protruding from the egg indicating a sucking predator had attacked the egg (Fig. 1b), "chewed" where eggs had been clearly fed upon by an organism with chewing mouthparts (Fig. 1c), "parasitized" where there was a distinct dark colored oviposition scar protruding slightly from the egg (Fig. 1d) or parasitoid emergence had occurred (Fig. 1e), and "unascribed" where eggs were unhatched and a direct cause of mortality could not properly be diagnosed. If there was no emergence of $H$. halys or parasitoids, eggs were dissected for signs of parasitism. If signs of parasitism were present eggs were classified as "parasitized" and if possible the "egg content" was identified to genus. If there were no signs of parasitism, they were considered "unascribed."

\section{Statistical analysis}

Percent egg mortality and parasitism per week in 2012 and 2013 were analyzed using linear regression. Each sampling "week" was defined as all sampling conducted within a
Table 1 Total number of trees sampled at each of the three nursery sites by species

\begin{tabular}{llllll}
\hline & \multicolumn{2}{l}{ Tree species } & & & \\
\cline { 2 - 5 } Site & Acer rubrum & Prunus serrulata & Ulmus americana & Ulmus parvifolia & Total \\
\hline 1 & 19 & 47 & 73 & - & 139 \\
2 & 28 & 20 & - & 31 & 79 \\
3 & 87 & 70 & 100 & - & 257 \\
Total & 134 & 137 & 173 & 31 & 475 \\
\hline
\end{tabular}

Site 1 = Raemelton Farm, Site 2 = Ruppert Nursery A, and Site $3=$ Ruppert Nursery B 
a

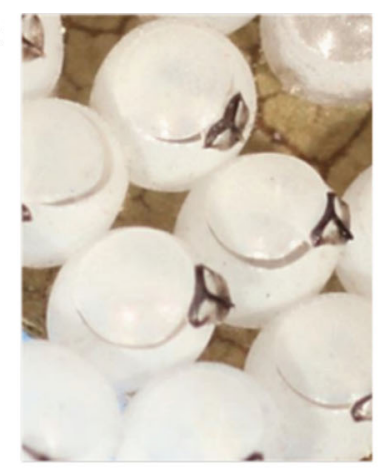

b

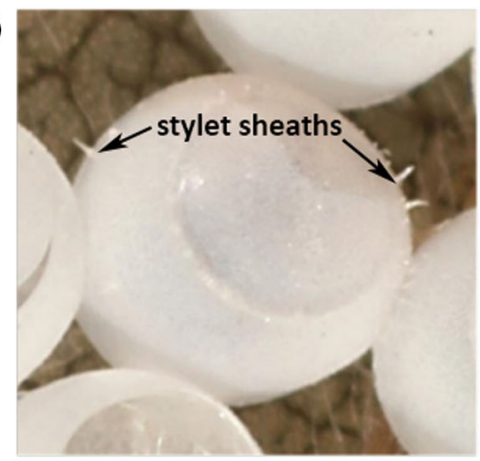

C

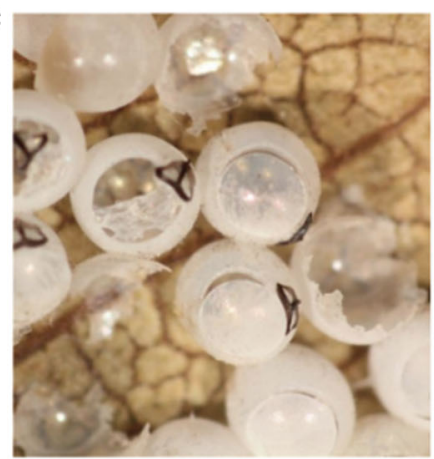

d

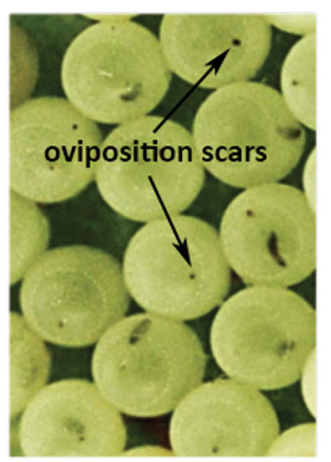

e

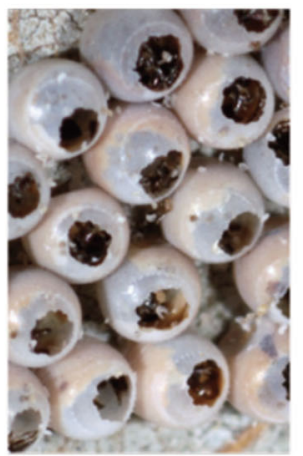

f

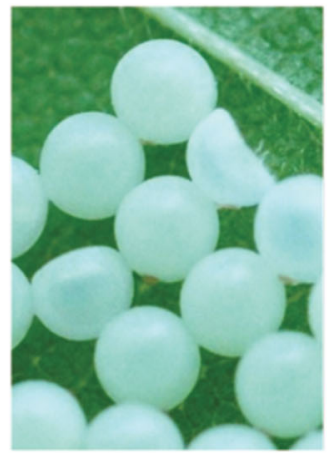

9

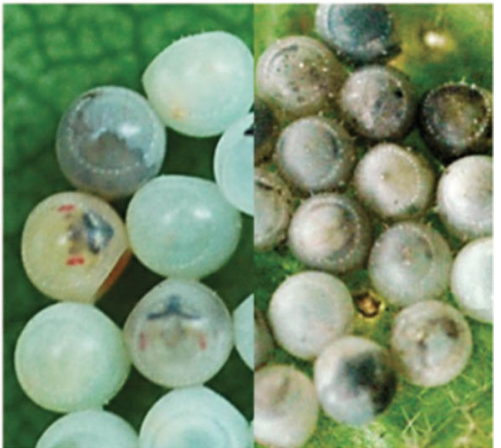

Fig. 1 Examples of brown marmorated stink bug (Halyomorpha halys) egg mortality factors. Shown are: a eggs where nymphs emerged (no mortality), b predation by haustellate insects with stylet sheaths protruding from eggs, $\mathrm{c}$ predation by mandibulate insects with jagged holes present on eggs, d parasitized eggs with brown

period of 7 days and consisted of up to two visits to each site. We compared mortality among different fate categories (parasitized, chewed, sucked, and unascribed) by year, tree species, nursery site, and egg exposure time using $\chi^{2}$ tests. Additionally, we tested the effects of year, tree species, site, and egg exposure time on each fate category using generalized linear models with a quasibinomial error distribution (Crawley 2012). Significance was then assessed with likelihood ratio $\chi^{2}$ and type II sums of squares. Tukey HSD tests were conducted when significant effects were observed. All analyses were conducted using R 3.3.2 (R Core Team 2016).

\section{Results}

A total of 897 and $1208 \mathrm{H}$. halys egg masses (24,124 and 32,073 eggs) were collected in 2012 and 2013, respectively (a total of 2105 egg masses and 56,197 eggs over 2 years). In both years, percent egg mortality was positively associated with sampling period (Fig. 2a). Percent egg mortality from all factors ranged from 27.93 to $88.89 \%$ per sampling period in 2012 and 25.03-100\% per sampling period in 2013 (Supplementary Table 1), while the overall oviposition scars and discoloration, e eggs with parasitoid emergence (exit holes have been chewed from discolored eggs), f indented eggs where mortality is unknown, and $\mathbf{g}$ unascribed mortality (eggs with varying discoloration and no signs of predation or parasitism)

mean percent egg mortality for each year was 53.83 and $54.44 \%$ in 2102 and 2013, respectively.

There were significant differences among $H$. halys egg fates for mortality factors by year $\left(\chi^{2}=13,565.00, d f=3\right.$, $p<0.001$; Fig. 3a), tree species $\left(\chi^{2}=1267.90, d f=9\right.$, $p<0.001 ; \quad$ Fig. $3 \mathrm{~b}), \quad$ site $\quad\left(\chi^{2}=2365.20, \quad d f=6\right.$, $p<0.001$; Fig. 3c), and egg exposure time $\left(\chi^{2}=363.76\right.$, $d f=3, p<0.001$; Fig. 3d). In 2012 and 2013 parasitism was by far the greatest source of mortality for $H$. halys eggs $($ mean $=35.84 \%)$ followed by unascribed mortality $($ mean $=11.20 \%), \quad$ and predation from chewing $($ mean $=4.61 \%)$ and sucking $($ mean $=2.53 \%)$ predators (Fig. 3a).

Parasitism was higher in 2013 than $2012\left(\chi^{2}=34.16\right.$, $d f=1, \quad p<0.001$; Fig. 3a), and was also higher on $P$. serrulata, $U$. americana, and $U$. parvifolia compared with $A$. rubrum host trees $\left(\chi^{2}=195.81, d f=3, p<0.001\right.$; Fig. 3b). Parasitism was also higher at site 1 (Raemelton Farm) and site 3 (Ruppert Nursery B) compared with site 2 (Ruppert Nursery A) $\left(\chi^{2}=55.14, d f=2, p<0.001\right.$; Fig. 3c). Egg exposure time did not affect parasitism $\left(\chi^{2}=0.58, d f=1, p=0.446\right.$; Fig. $\left.3 \mathrm{~d}\right)$.

Although predation by chewing predators was relatively low, it was higher on $U$. americana compared with the 

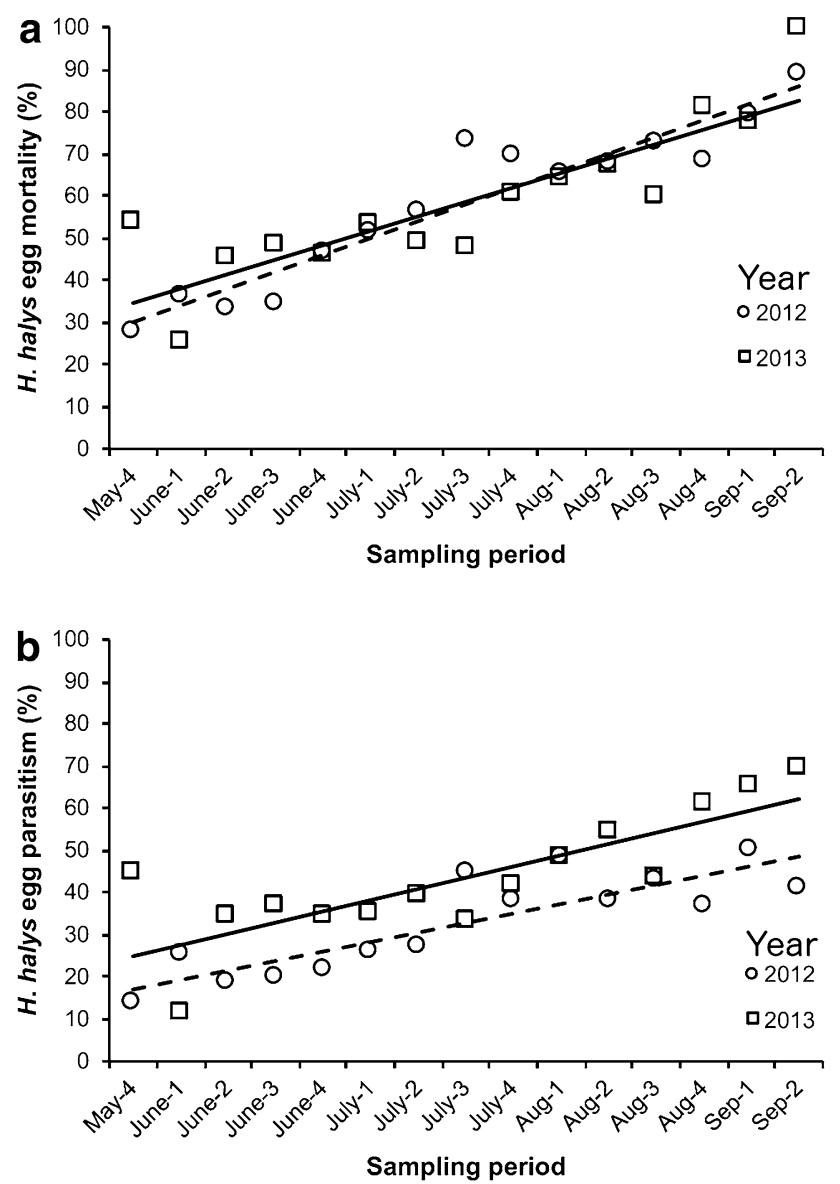

Fig. 2 Shown are: a percent mortality of brown marmorated stink bug (Halyomorpha halys) eggs over time in 2012 $\left(y=4.00 \mathrm{x}+25.99, \quad R^{2}=0.892, \quad d f=1, \quad p<0.001\right)$ and 2013 $\left(y=3.43 \mathrm{x}+31.14, R^{2}=0.709, d f=1, p<0.001\right)$, and $\mathbf{b}$ percent parasitism of brown marmorated stink bug eggs over time in 2012 $\left(y=2.25 \mathrm{x}+14.74, \quad R^{2}=0.718, \quad d f=1, \quad p<0.001\right)$ and 2013 $\left(y=2.66 \mathrm{x}+22.19, R^{2}=0.628, d f=1, p<0.001\right)$. The number following each month indicates the week of that month in which sampling occurred, i.e., May-4 is the fourth week in May

other host trees $\left(\chi^{2}=8.08, d f=3, p=0.044\right.$; Fig. 3b) and was also higher at site 2 (Ruppert Nursery A) than the other 2 sites $\left(\chi^{2}=25.90, d f=2, p<0.001\right.$; Fig. $\left.3 c\right)$. We also found that chewing predation was greater when eggs were left exposed for 7 days compared with 2 days $\left(\chi^{2}=26.79, d f=1, p<0.001\right.$; Fig. $\left.3 \mathrm{~d}\right)$. There was no effect of year on chewing predation $\left(\chi^{2}=2.02, d f=1\right.$, $p=0.156$; Fig. 3a).

Sucking predation was only significantly affected by egg exposure time $\left(\chi^{2}=12.80, d f=1, p<0.001\right.$; Fig. $\left.3 \mathrm{~d}\right)$, with more sucking predation when eggs were exposed to natural enemies for 7 days (2.80\%) compared with 2 days (1.40\%). Year $\left(\chi^{2}=0.03, d f=1, p=0.854\right.$; Fig. 3a), tree species $\left(\chi^{2}=2.24, d f=3, p=0.524\right.$; Fig. 3b), and site $\left(\chi^{2}=2.11, d f=2, p=0.349\right.$; Fig. $\left.3 \mathrm{c}\right)$ did not significantly affect sucking predation.
Unascribed mortality was only affected by year $\left(\chi^{2}=28.63, d f=1, p<0.001\right.$; Fig. $\left.3 a\right)$, with $14.50 \%$ in 2012 compared with $8.75 \%$ in 2013. Tree species $\left(\chi^{2}=5.48, d f=2, p=0.140\right.$; Fig. $\left.3 b\right)$, site $\left(\chi^{2}=4.93\right.$, $d f=2, \quad p=0.085$; Fig. $3 c)$, and egg exposure time $\left(\chi^{2}=0.09, d f=1, p=0.760\right.$; Fig. $\left.3 \mathrm{~d}\right)$ did not significantly affect unascribed mortality.

As parasitism represented the largest source of mortality, we examined how it varied by sampling period each year. In both years, percent parasitism increased over time (Fig. 2b). Percent egg parasitism ranged from 13.89 to $50.21 \%$ in 2012 and $11.31-69.37 \%$ in 2013. Parasitism of egg masses (one or more eggs parasitized within the egg mass) was $47.05 \%$ in 2012 and $52.48 \%$ in 2013 . We observed 15,357 enclosed parasitoid adults from egg masses in this study (5638 and 9719 in 2012 and 2013, respectively). The species observed included seven native parasitoids: A. reduvii, A. pearsalli, A. mirabilis, Tr. brochymenae, Tr. euschisti, Te. podisi, and Ooencyrtus sp. (Table 2). The most abundant species by far was A. reduvii comprising 61.17 and $79.12 \%$ of all parasitoids in 2012 and 2013, respectively (Table 2). Anastatus spp. account for $98.32 \%$ of parasitism as determined from eclosed parasitoids. The sex ratio of the most dominant genus of parasitoid, Anastatus spp. (male: female) was 1:2.05 in 2012 and 1:4.86 in 2013. Although the other genera of parasitoids were far less abundant than Anastatus, a similar trend was also observed for Telenomus spp. (1:1 in 2012, and 1:10.5 in 2013) and Trissolcus spp. (1:9.44 in 2012, and 1:29.75 in 2013).

\section{Discussion}

Biological control is considered to be a sustainable or longterm solution for managing local and invasive pest species. Classical biological control is most commonly thought of for the mitigation of exotic pests (Kenis et al. 2017). However, some may contend it is equally important to consider augmentative or conservation biological control tactics to suppress invasive pest species. Toward this end, it is essential to identify and determine the impact of native natural enemies associated with a pest in its invaded range. This will provide insight on the likelihood that one or more native natural enemies can be successful used in augmentative or conservation biological control programs.

This study provides one of the most rigorous assessments of the identity and impact of indigenous natural enemies on $H$. halys egg mortality. More than 56,000 naturally laid eggs were monitored in woody ornamental nurseries. Halyomorpha halys egg mortality overall averaged $54 \%$ both years of the study and parasitism was markedly the greatest cause of egg mortality (35.8\%), 

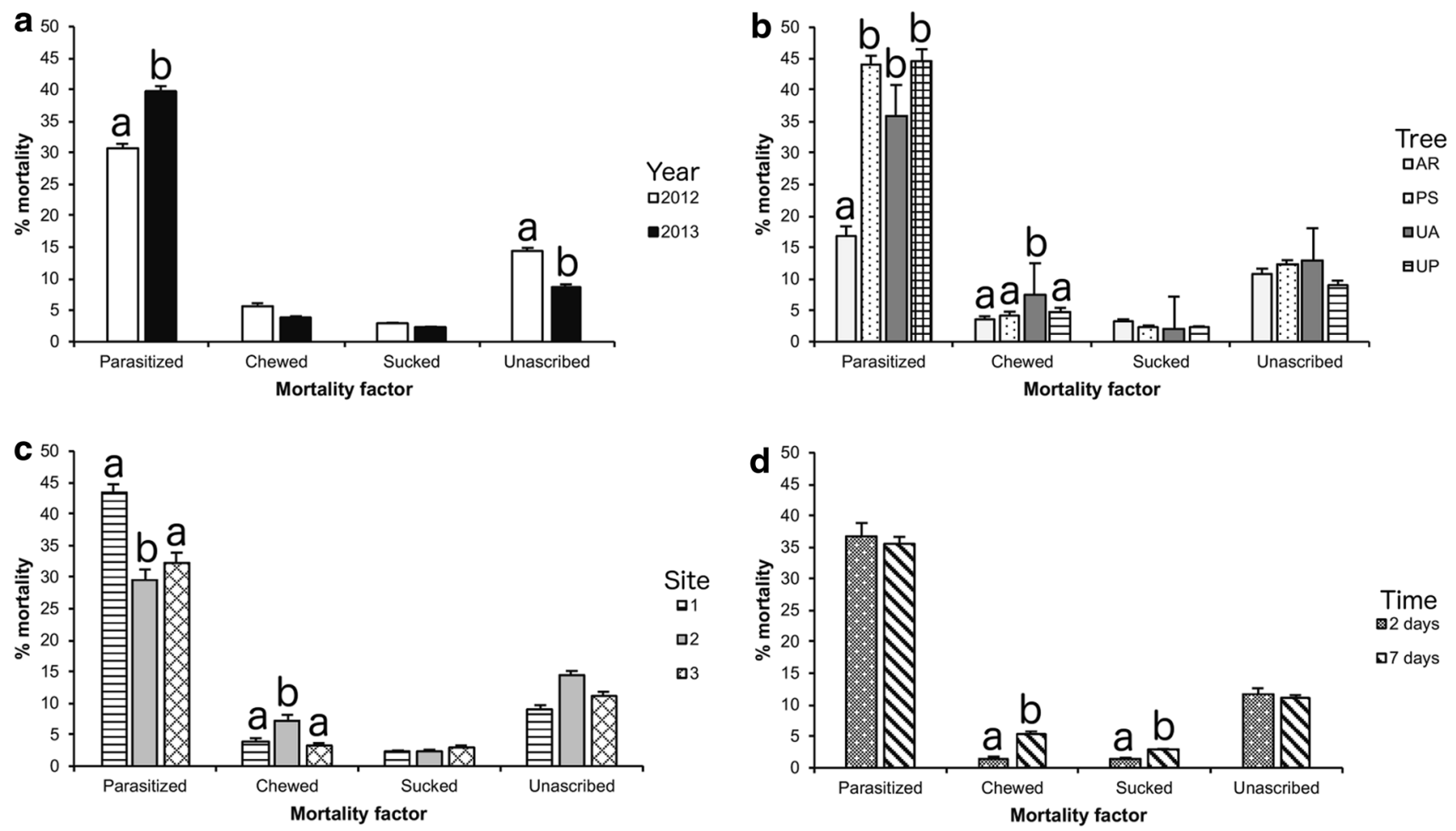

Fig. 3 Fates of brown marmorated stink bug (Halyomorpha halys) eggs by: a year, $\mathbf{b}$ tree species, $\mathbf{c}$ site, and $\mathbf{d}$ egg exposure time. Mean percent egg mortality for each category of mortality pooled by week. Bars represent means and lines represent standard errors. For each mortality factor separately, different lowercase letters represent

factors that were significantly different from each other $(p<0.05)$. Tree species are: AR Acer rubrum, PS Prunus serrulata, UA Ulmus americana, and UP Ulmus parvifolia. Sites are: $1=$ Raemelton Farm, $2=$ Ruppert Nursery A, and $3=$ Ruppert Nursery B
Table 2 Summary of the abundance and identity of eclosed hymenopteran parasitoid adults collected from brown marmorated stink bug (Halyomorpha halys) eggs in ornamental nurseries in Maryland

\begin{tabular}{|c|c|c|c|c|c|}
\hline \multirow[b]{2}{*}{ Genus } & \multirow[b]{2}{*}{ Species } & \multicolumn{2}{|l|}{2012} & \multicolumn{2}{|l|}{2013} \\
\hline & & $n$ & Relative abundance (\%) & $n$ & Relative abundance $(\%)$ \\
\hline \multirow[t]{4}{*}{ Anastatus } & mirabilis & 46 & 0.82 & 119 & 0.63 \\
\hline & pearsalli & 218 & 3.87 & 215 & 1.98 \\
\hline & Reduvii & 3449 & 61.17 & 9031 & 79.12 \\
\hline & sp. & 1811 & 32.12 & 208 & 16.77 \\
\hline Ooencyrtus & sp. & 16 & 0.28 & 0 & 0 \\
\hline \multirow[t]{2}{*}{ Telenomus } & podisi & 2 & 0.04 & 21 & 0.19 \\
\hline & sp. & 2 & 0.04 & 2 & 0.05 \\
\hline \multirow[t]{3}{*}{ Trissolcus } & brochymenae & 64 & 1.14 & 103 & 0.96 \\
\hline & euschisti & 21 & 0.37 & 16 & 0.17 \\
\hline & sp. & 9 & 0.16 & 4 & 0.14 \\
\hline Total & & 5638 & & 9719 & \\
\hline
\end{tabular}

compared to chewing and sucking predation (7\%) or unknown causes (11.2\%). In both years, parasitism increased over the season and from 2012 to 2013. In addition to seasonal differences, parasitism rates were influenced by tree species, study site location, and egg exposure time in the field. Although seven native parasitoid species emerged from $H$. halys eggs during the 2-year study (Table 2), A. reduvii was the most abundant, making up 61.2 and $79.2 \%$ in 2012 and 2013, respectively. The 3 Anastatus spp. as a group accounted for $98.3 \%$ of parasitism.

Results from the present study are similar to an earlier, but much smaller, study in ornamental plant nurseries that compared the parasitoid community and parasitism rates on naturally field laid egg masses to sentinel (live) egg masses of $H$. halys (Jones et al. 2014). In the latter study, naturally 
laid eggs of $H$. halys incurred parasitism rates as high as 28.4 and $55.3 \%$ over the 2-year study and six native egg parasitoids were detected parasitizing $H$. halys eggs. Anastatus spp. made up $99.3 \%$ of the parasitoid community, while scelionid egg parasitoids rarely $(0.7 \%)$ emerged from $H$. halys eggs. As with the present study, A. reduvii was also the most abundant parasitoid species (Jones et al. 2014)

Other studies have been conducted to examine the community composition of parasitoids and other native natural enemies associated with $H$. halys in the mid-Atlantic and north east region of the U.S. Studies have been conducted in a range of habitat types (woody plots, landscape plots, and fruit, vegetable, and row crop systems) (Cornelius et al. 2016; Herlihy et al. 2016; Ogburn et al. 2016). Although a variety of factors may affect species of parasitoids found within a habitat, there is data suggesting that some of these species are habitat specialists, and $H$. halys egg parasitism has generally been found to be higher in arboreal habitats (Cornelius et al. 2016; Herlihy et al. 2016). For example, in the present study in nurseries which are arboreal habitats, Anastatus spp. followed by Trissolcus spp. were the most abundant, while other genera (Telenomus and Ooencyrtus) were found at very low abundances $(0-0.28 \%$ of parasitoids). Similarly, research in two other types of arboreal habitats, experimental landscape plots and woodlots, found just two parasitoid species, Tr. euschisti and A. reduvii, in both habitats (Cornelius et al. 2016). Additionally, Herlihy et al. (2016) studied parasitoid activity on $H$. halys eggs in three habitat types, woods, orchards (both arboreal), and soybean fields, and found 2 native (Tr. euschisti and Tr. brochmymenae) and 1 exotic (Tr. japonicus) parasitoid occurred more often in woods habitat, $A$. reduvii was exclusively in orchard, and $T e$. podisi was exclusively recovered in soybean. Therefore, these studies including the present depict a preference of Anastatus and Trissolcus species for arboreal habitats, and Telenomus and Ooencyrtus species for agricultural crops which support of earlier findings (Okuda and Yeargan 1998; Serrano and Foltz 2003; Qiu 2007; Hou et al. 2009; Maltese et al. 2012; Danne et al. 2013).

Within a habitat, host plant composition can influence rates of parasitism and predation. We found significant differences in parasitism among different host trees with Acer having the lowest rates and Prunus and Ulmus having significantly higher rates (Fig. 3b). Our results support variation noted by Cornelius et al. (2016) who also found parasitism was significantly higher on Prunus compared to Acer. This difference was attributed mainly to A. reduvii which was the most prevalent native parasitoid recovered (Cornelius et al. 2016). These results suggest other factors besides an arboreal habitat, may also be influencing the activity of $A$. reduvii such as differences in $H$. halys abundance on different tree species (Bergmann et al. 2016). Greater plant species richness has been shown to support greater abundance of natural enemies due largely to the presence of diverse communities of alternate prey (Shrewsbury and Raupp 2006). Ornamental plant nurseries provide a wide variety of host plants that support a diversity of Hemiptera and Lepidoptera that may serve as reservoirs of alternate hosts for $A$. reduvii and enhance its ability to impact $H$. halys in both nurseries and other arboreal habitats. Altogether, these results suggest that conservation biological control may be implemented to favor natural enemies such as incorporating tree species that support high rates of parasitism or alternate hosts for generalist natural enemies into the managed habitat.

In addition to habitat type, the type of egg mass used may also affect egg mortality. The present study used only egg masses that were laid naturally in the field, whereas other studies frequently used a combination of naturally laid and 2 types of sentinel egg masses [i.e., laboratoryreared eggs that were fresh (live) or frozen (dead)]. Some work has suggested that sentinel (live) egg masses of $H$. halys significantly underestimate parasitism rates, parasitoid community composition, and parasitoid species richness (Jones et al. 2014), while other research has found that native parasitoids emerge more frequently from frozen than fresh eggs (Haye et al. 2015; Herlihy et al. 2016).

There are several possible factors influencing the success rate of native parasitoids attacking exotic $H$. halys eggs in its invaded range. In the present study, Anastatus species, especially $A$. reduvii, were significantly more successful at completing development in $H$. halys eggs than Trissolcus species. A similar pattern was found in Europe where the only native parasitoids to successfully develop in H. halys were A. bifasciatus and Ooencyrtus telenomicida (Haye et al. 2015; Rondoni et al. 2017). Anastatus reduvii and A. bifasciatus are generalist egg parasitoids across several orders of insects (ex. Hemiptera, Lepidoptera, Orthoptera) (Howard 1880; Krombein et al. 1979; Mendel et al. 1989; Hou et al. 2009; Haye et al. 2015) whereas Trissolcus species are egg parasitoids specific to the superfamily Pentatomoidea (Yang et al. 2009). A possible explanation for differences in parasitism between native parasitoid species on exotic hosts is that generalist and specialist parasitoids differ in their ability to overcome or adapt to new host defensive responses (Vinson 1990; Haye et al. 2015). Generalist parasitoids interact with a variety of defensive responses from their hosts and should be better adapted at overcoming host defenses than specialist parasitoids that encounter fewer defenses (Vinson 1990; Haye et al. 2015). Not surprisingly, over time introduced species tend to be attacked by increasing numbers of native parasitoids as they likely adapt to defenses (Cornell and Hawkins 1993; Hawkins and Cornell 1994; Haye et al. 
2015). This supposition is further supported by studies that show that native European and North American Trissolcus and other parasitoid species that do not successfully develop in naturally laid or sentinel live eggs are successful on frozen eggs whose defensive responses are likely compromised (Haye et al. 2015; Herhily et al. 2016). In contrast, the Asian Tr. japonicus and Tr. cultratus share a coevolved history with $H$. halys in Asia and have likely adapted to defensive responses of $H$. halys.

Anastatus species have a history of successful biological control as different species of Anastatus were released against several pest species with parasitism ranging from $23 \%$ to greater than $90 \%$ (Huang et al. 1974; Fay and De Faveri 1997; Qiu 2007; Hou et al. 2009; Danne et al. 2013). A native Asian Anastatus species was tested against $H$. halys in Beijing with parasitism rates ranging from 52.6 to 64.7\% (Hou et al. 2009). In Europe, studies have shown the only native parasitoid to successfully develop consistently in $H$. halys is A. bifasciatus (Haye et al. 2015). In the present study, we observed Anasatus spp. parasitizing $H$. halys eggs at a rate of approximately $98 \%$. Together these studies show strong support for Anastatus spp. as a good candidate for use in augmentative biological control programs targeting $H$. halys.

Anastatus and all other genera of parasitoids in our study showed an interesting change in sex ratios. This shift in sex ratio from male to female bias may be due to an increase in host resource (more H. halys eggs). Many ovipositing parasitoids respond to the traces of other females by increasing the proportion of male progeny (Hamilton 1967; Liljesthrom et al. 2013). Therefore, it is possible that male production decreased due to greater resource availability likely reducing the chances of female parasitoid interaction.

Findings from the present study suggest a number of interesting directions for future research. For instance, although interspecific interactions among parasitoids were not directly examined, parasitism rates or outcomes may be influenced by factors such as multi-parasitism, egg guarding by adult parasitoids, or competition between adult parasitoids (Abram et al. 2014; Haye et al. 2015; Konopka et al. 2016). Consequently, it will be especially interesting to study interactions between native parasitoids and the exotic $T r$. japonicas that has adventive populations in the U.S. (Talamas et al. 2015; Herlihy et al. 2016; Milnes and Beers 2016). Additionally, in the present study, all unhatched eggs in which no parasitoids emerged, were dissected for signs of underdeveloped or developed parasitoids that may have killed the egg but failed to egress. If no parasitoid was found, the egg was classified as unascribed. As such, some of the unascribed mortality may have been caused by parasitoids. This conjecture is further strengthened by the fact that there was a change (increase) in parasitism rate from 2012 to 2013, which coincided with an inverse change (decrease) in unascribed egg mortality. If this was indeed the case it suggests no change in parasitism when direct and potential indirect effects of parasitoids are combined. Therefore, parasitism attempts by parasitoid species other than Anastatus may actually be more common than indicated by parasitoid emergence data (Abrams et al. 2014; Haye et al. 2015).

In summary, we quantified $H$. halys egg mortality and identified indigenous egg parasitoids attacking $H$. halys eggs in ornamental nurseries. The results of this study and others indicate that Anastatus spp., particularly A. reduvii, are strong candidates for use in biological control programs. Anastatus spp. are generalist parasitoids that provide high rates of parasitism of $H$. halys in nurseries, and have been used successfully in augmentative biological control programs against other Heteropteran pests in different systems. This is strong evidence that $A$. reduvii is an excellent candidate for use in augmentative biological control. Conservation biological control targeting not only Anastatus species but also predators may be possible in nursery or other arboreal habitats. Anastatus is arboreal, and parasitism rates were affected by habitat factors such as tree species (significantly lower on maple than other than other trees tested), and study location. Although predation rates were lower than parasitism, they still impacted $H$. halys egg mortality. Predation also was affected by habitat factors. These results suggest habitats could be manipulated to favor parasitoids and predators. Results from this study provide evidence that future research should focus on native Anastatus spp., particularly A. reduvii, and their use in both augmentative and conservation biological control programs, in addition to conservation of predators. The data on indigenous natural enemy communities attacking $H$. halys in the present study could provide a useful baseline for comparisons in studies on the interactions between the native $A$. reduvii and the exotic $T r$. japonicus egg parasitoids and their impact on biological control of $H$. halys in the USA.

\section{Author contributions statement}

All authors conceived and designed this study. ALJ conducted experiments. ALJ and DEJ analyzed the data. All the authors contributed substantially to the writing and editing of the manuscript. All authors approved the final manuscript

Acknowledgements We are grateful to Steve Black, Kelly Lewis, and Nick Graves for their cooperation and nursery access. We also thank Kelly Jackson, Stokes Aker, Caroline Brodo, Rory Peabody, Christopher Riley, and Ryan Wallace for field assistance. The authors appreciate the input from 2 anonymous reviewers. This work was 
supported by funds from the USDA National Institute of Food and Agriculture (NIFA) McIntire-Stennis Project (Project No. 1003486) and USDA NIFA Specialty Crop Research Initiative (Award 2011-51181-30937).

\section{Compliance with ethical standards}

Conflict of interest The authors declare that they have no conflict of interest.

Ethical approval This article does not contain any studies with human participants or animals (vertebrates) performed by any of the authors.

Open Access This article is distributed under the terms of the Creative Commons Attribution 4.0 International License (http://crea tivecommons.org/licenses/by/4.0/), which permits unrestricted use, distribution, and reproduction in any medium, provided you give appropriate credit to the original author(s) and the source, provide a link to the Creative Commons license, and indicate if changes were made.

\section{References}

Abram PK, Gariepy TD, Boivin G, Brodeur J (2014) An invasive stink bug as an evolutionary trap for an indigenous egg parasitoid. Biol Invas 16:1387-1395

Aukema JE, Leung B, Kovacs K, Chivers C, Britton KO, Englin J, Frankel SJ, Haight RG, Holmes TP, Liebhold AM, McCullough DG, Von Holle B (2011) Economic impacts of non-native forest insects in the continental United States. PLoS ONE 6:e24587. doi:10.1371/journal.pone.0024587

Bergh JC, Morrison WR, Joseph SV, Leskey TC (2017) Characterizing spring emergence of adult Halyomorpha halys using experimental overwinering shelters and commercial pheromone traps. Entomol Exp Appl 162:336-345. doi:10.1111/eea.12539

Bergmann E, Bernhard KM, Bernon G, Bickerton M, Gill S, Gonzales C, Hamilton GC, Hedstrom C, Kamminga K, Koplinka-Loehr C, Krawczyk G, Kuhar TP, Kunkel B, Lee J, Leskey TC, Martinson H, Nielsen AL, Raupp M, Shearer P, Shrewsbury P, Walgenbach J, Whalen J, Wiman N (2013) Host plants of the brown marmorated stink bug in the U.S. http://www.stopbmsb.org/ where-is-bmsb/host-plants/\#host_plants_table. Accessed 20 Jan 2017

Bergmann EJ, Venugopal PD, Martinson HM, Raupp MJ, Shrewsbury PM (2016) Host plant use by the invasive Halyomorpha halys (Stål) on woody ornamental trees and shrubs. PLoS ONE 11:e0149975

Bernon G (2004) Biology of Halyomorpha halys, the brown marmorated stink Bug (BMSB). In: Final report-USDA APHIS CPHST, p 17

Chu F, Zhou Z, Li R, Liu X (1997) Study on control and observation of the bionomics characteristics of Halyomorpha picus Fabricius. J Hebei Agric Univ 2:12-17

Cornell HV, Hawkins BA (1993) Accumulation of native parasitoid species on introduced herbivores-a comparison of hosts as natives and hosts as invaders. Am Nat 141:847-865

Cornelius ML, Dieckhoff C, Hoelmer KA, Olsen RT, Weber DC, Herlihy MV, Talamas EJ, Vinyard BT, Greenstone MH (2016) Biological control of sentinel egg masses of the exoic invasive stink bug Halyomorpha halys (Stål) in mid-Atlantic USA ornamental landscapes. Biol Control 103:11-26

Crawley MJ (2012) The R Book, 2nd edn. Wiley, Chichester
Danne AW, Llewellyn R, Huwer RK, Furlong MJ (2013) Fruitspotting bugs, Amblypelta nitida Stål and A. lutescens lutescens Distant (Hemiptera: Coreidae): a review of the potential for integrated management practices. Aust Entomol 53:112-123Fay HAC, De Faveri SG (1997) Egg parasitoids of fruitspotting bugs (Amblypelta spp.): potential for their mass-rearing and strategic release. In: Final report HG308. Queensland Department of Primary Industries, Mareeba., p 23

Hamilton WD (1967) Extraordinary sex ratios. Science 156:477-488

Hamilton G (2009) Brown marmorated stink bug. Am Entomol 55:19-20

Hawkins BA, Cornell HV (1994) Patterns of parasitoid accumulation on introduced herbivores. In: Hawkins BA, Sheehan W (eds) Parasitoid community ecology. Oxford University Press, New York, pp 77-90

Haye T, Fischer S, Zhang J, Gariepy T (2015) Can native egg parasitoids adopt the invasive brown marmorated stink bug, Halyomorpha halys (Heteroptera: Pentatomidae), in Europe? J Pest Sci 88:693-705. doi:10.1007/s10340-015-0671-1

Herlihy MV, v EJ, Weber DC (2016) Attack and success of native and exotic parasitoids on eggs of Halyormorpha halys in three Maryland habitats. PLoS ONE 11:e0150275ADD

Hoebeke ER, Carter ME (2003) Halyomorpha halys (Stal) (Heteroptera: Pentatomidae): a polyphagous plant pest from Asia newly detected in North America. Proc Entomol Soc Wash 105:225-237

Hou Z, Liang H, Chen Q, Hu Y, Tian H (2009) Application of Anastatus sp. against Halyomorpha Halys. For Pest Dis 28:39-43

Howard LO (1880) Two new species of Eupelmus, with remarks on E. (Antigaster) mirabilis. Walsh Can Entomol 12:207-210

Huang MD, Mai H, Wu WN, Poo CL (1974) The bionomics of Anastatus sp. and its utilisation for control of Tessaratoma papillosa Drury. Acta Entomol Sin 17:362-375

Jones AL, Jennings DE, Hooks CRR, Shrewsbury PM (2014) Sentinel eggs underestimate rates of parasitism of the exotic brown marmorated stink bug, Halyomorpha halys. Biol Control 78:61-66

Keane RM, Crawley MJ (2002) Exotic plant invasioins and the enemy release hypothesis. Trends Ecol Evol 17:164-170

Kenis M, Hurley BP, Hajek AE, Cock MJW (2017) Classical biological control of insect pests of trees: facts and figures. Biol Invasions. doi:10.1007/s10530-017-1414-4

Konopka JK, Haye T, Griepy T, Mason P, Gillespie D, McNeil JN (2016) An exotic parasitoid provides an invasional lifeline for native parasitoids. Ecol Evol. doi:10.1002/ece3.2577

Krombein K, Hurd PD, Smith DR, Burks BD (1979) Catalog of Hymenoptera in America North of Mexico. Smithsonian Institution Press, Washington. doi:10.5962/bhl.title.5074

Leskey TC, Hamilton G, Nielsen AL, Polk DF, Rodriguez-Saona C, Bergh JC, Herbert A, Kuhar TP, Pfeiffer D, Dively GP, Hooks CRR, Raupp MJ, Shrewsbury PM, Krawczyk G, Shearer PW, Whalen J, Koplinka-Loehr C, Myers E, Inkley D, Hoelmer KA, Lee DH, Wright SE (2012) Pest status of the brown marmorated stink bug, Halyomorpha halys in the USA. Outlook Pest Manag 23:218-226

Leskey TC, Agnello A, Bergh JC, Dively GP, Hamilton GC, Jentsch P, Khrimian A, Krawczyk G, Kuhar TP, Lee DH, Morrison WR, Polk DF, Rodriguez-Saona C, Shearer PW, Short BD, Shrewsbury PM, Walgenbach JF, Weber DC, Welty C, Whalen J, Wiman N, Zaman F (2015) Attraction of the invasive Halyomorpha halys (Hemiptera: Pentatomidae) to traps baited with semiochemical stimuli across the United States. Environ Entomol 44:746-756. doi:10.1093/ee/nvv049

Liljesthrom GG, Cingolani MF, Rabinovich JE (2013) The functional and numerical responses of Trissolcus basalis (Hymenoptera: 
Platygastridae) parasitizing Nezara viridula (Hemiptera: Pentatomidae) eggs in the field. Bull Entomol Res 103:441-450

Maltese M, Caleca V, Guerrier E, Strong WB (2012) Parasitoids of Leptoglossus occidentalis Heidemann (Heteroptera: Coreidae) recovered in western North America and first record of its egg parasitoid Gryon pennsylvanicum (Ashmead) (Hymenoptera: Platygastridae) in California. Pan Pac Entomol 88:347-355

Mendel MJ, Shaw PB, Owens JC, Richman DB (1989) Developmental rates, thresholds and thermal constants of the egg parasitoid Anastatus-semiflavidus (Hymenoptera, Eupelmidae) and its host Hemileuca olivae (Lepidoptera, Saturniidae). J Kansas Entomol Soc 62:300-306

Milnes J, Beers EH (2016) Discovery of an exotic egg parasitoid of the brown marmorated stink bug and its potential for biocontrol in Washington State. In: 90th Annual meeting, orchard pest \& disease management conference, 13-15 January, 2016, Portland Hilton, Portland, OR

Morrison WR, Mathews CR, Leskey TC (2016) Frequency, efficiency, and physical characteristics of predation by generalist predators of brown marmorated stink bug (Hemiptera: Pentatomidae) eggs. Biol Control 97:120-130

Naranjo SE, Ellsworth PC, Frisvold GB (2014) Economic value of biological control in integrated pest management of managed plant systems. Annu Rev Entomol 60:621-645. doi:10.1146/ annurev-ento-010814-021005

Ogburn EC, Bessin R, Dieckhoff C, Dobson R, Grieshop M, Hoelmer KA, Mathews C, Moore J, Nielsen AL, Poley K, Pote JM, Rogers M, Welty C, Walgenbach JF (2016) Natural enemy impact on eggs of the invasive brown marmorated stink bug, Halyomorpha halys (Stål) (Hemiptera: Pentatomidae), in organic agroecosystems: a regional assessment. Biol Control 101:39-51

Okuda MS, Yeargan KV (1998) Habitat partitioning by Telenomus podisi and Trissolcus euschisti (Hymenoptera: Scelionidae) between herbaceous and woody host plants. Environ Entomol 17:795-798

Pimentel D, Morrison D, Zuniga R (2005) Update on the environmental and economic costs associated with alien-invasive species in the United States. Ecol Econ 52:273-288

Qiu LF (2007) Studies on biology of the brown-marmorated stink bug, Halyomorpha halys (Stål) (Hemiptera: Pentatomidae), an important pest for pome trees in China and its biological control. Dissertation, Chinese Academy of Forestry, Beijing, China
Rice K, Bergh C, Bergman E, Biddinger D, Dieckhoff C, Dively G, Fraser H, Gariepy T, Hamilton G, Haye T, Herbert A, Hoelmer K, Hooks CRR, Jones A, Krawczyk G, Kuhar T, Martinson H, Mitchell W, Nielsen AL, Pfeiffer DG, Raupp MJ, RodriguezSaona C, Shearer P, Shrewsbury P, Venugopal PD, Whalen J, Wiman NG, Leskey TC, Tooker JF (2014) Biology, ecology, and management of brown marmorated stink bug (Halyomorpha halys). J Integr Pest Manag 5:A1-A13. doi:10.1603/ IPM14002

R Core Team (2016) R: a language and environment for statistical computing. R Foundation for Statistical Computing, Vienna, Austria. http://www.r-project.org. Accessed 15 Nov 2016

Rondoni G, Bertoldi V, Malek R, Foti MC, Peri E, Maistrello L, Haye T, Conti E (2017) Native egg parasitoids recorded from the invasive Halyomorpha halys successfully exploit volatiles emitted by the plant-herbivore complex. J Pest Sci. doi:10.1007/ s10340-017-0861-0

Santacruz EN, Venette R, Dieckhoff C, Hoelmer K, Koch RL (2017) Cold tolerance of Trissolcus japonicus and T. cultratus, the potential biological control agents of Halyomorpha halys, the brown marmorated stink bug. Biol Control 107:11-20

Serrano D, Foltz JL (2003) Natural history of Anisota peigleri (Lepidoptera: Saturniidae) in Gainesville, Florida. Fla Entomol 86:217-218

Shrewsbury PM, Raupp MJ (2006) Do top-down or bottom-up forces determine Stephanitis pyrioides abundance in urban landscapes? Ecol Appl 16:262-272

Talamas EJ, Herlihy MV, Dieckhoff C, Hoelmer K, Buffington M, Bon MC, Weber DC (2015) Trissolcus japonicus (Ashmead) (Hymenoptera, Scelionidae) emerges in North America. J Hymenopt Res 43:119-128

Vinson SB (1990) How parasitoids deal with the immune system of their host: an overview. Arch Insect Biochem 13:3-27

Yang ZQ, Yao YX, Qiu LF, Li ZX (2009) A new species of Trissolcus (Hymenoptera: Scelionidae) parasitizing eggs of Halyomorpha halys (Heteroptera: Pentatomidae) in China with comments on its biology. Ann Entomol Soc Am 102:39-47

Zhang CT, Li DL, Su HF, Xu GL (1993) A study on the biological characteristics of Halyomorpha picus and Erthesina fullo. For Res 6:271-275 